\title{
A FIGURA DO REI GUERREIRO NA GESTA PRINCIPIUM POLONORUM
}

Paulo Romanowski

\section{1 - Apresentação}

A Gesta principium Polonorum foi escrita entre os anos de 1112-1116 por um autor que se intitulava de anônimo. O texto mostra que este tinha ligação com a Provença, por isso ficou este monge anônimo conhecido como Galo Anônimo. A sua crônica sobre os feitos dos reis polanos, os Piastes, é a primeira fonte régia desse grupo humano que entra para a Cristandade medieval no século $\mathrm{X}$, por meio dos missionários vindos do Império Romano Germânico. Escolhemos realizar um ensaio sobre a construção da figura do rei guerreiro pelo fato do imaginário social medieval ligar os reis ao serviço militar. Fazendo, assim, aquele que constrói sua figura guerreira da maneira mais eficiente, um indivíduo com direitos superiores dentro da comunidade. Os Piastes passavam por uma crise hierárquica que começou no século XI, por isso no inicio do XII o Rei Bolesław III tenta recuperar sua posição de hegemonia social por meio da cultura escrita, patrocinando assim Galo Anônimo é dando ao binômio: Cultura e poder mais uma faceta. Passamos a análise da figura guerreira do Rei polano.

\section{2 - A importância da figura militar dentro da sociedade medieval}

O texto de Galo Anônimo traz como uma das qualidades do soberano Piaste, desde seu passado inicial, a glória da guerra, a vitória na batalha e a sabedoria do combate. Essa qualidade está até nas palavras usadas pelo monge, pois Bolesław III é adjetivado como sendo "o filho de Marte"1 e sua capacidade marcial existe desde sua

${ }^{1}$ Puer martis (GALLUS, Anonymus. Gesta principium Polonorum. The Deeds of The Princes of the Poles. trad. para o inglês de Paul W. Knoll \& Frank Schaer. 
infância, que é repleta de feitos incríveis como a capacidade de derrotar um urso ${ }^{2}$. As palavras, ao descrever os primeiros anos de vida do garoto Bolesław, são construídas para apresentá-lo como alguém que tem o traço de habilidade militar, como vemos nesta passagem: "Então havia grande esperança num menino com tão boas qualidades e em quem já se mostravam claros sinais de glória marcial"3. Isso demonstra que a qualidade militar tem uma importância chave na edificação da figura do rei polano.

A sociedade medieval tem na guerra um elemento importante, pois ela serve de critério para a configuração do indivíduo como sendo pleno para o exercício de uma função laica de autoridade. A crônica dos Polanos apresenta o rei piaste como um guerreiro, que tem uma virtude importante para o imaginário da época, algo que transpassa o tempo, uma virtude social medieval que prova como o escrito de Galo Anônimo é parte integrante de seu momento. O rei guerreiro é o nosso ponto de análise neste artigo sobre uma das figuras construída na $G p P^{4}$. Passamos a ver a sua importância no recorte de tempo de nossa pesquisa. Apresentaremos os pontos que interessam a nós para o entendimento das possíveis explicações sobre a necessidade de nosso cronista produzir várias passagens que fomentam a predestinação guerreira do rei polano. O monge coloca dentro de sua crônica a meta do texto, em suas palavras: "Eu escrevo sobre a guerra dos reis e duques e não um evangelho"5. Assim, iniciamos falando de todo o aparato social que cerca o produtor e a obra para entendermos a conjuntura intelectual da fonte de trabalho.

Budapeste/New York: Central European University Press, 2003. p. 136). Utilizaremos o texto latino como base para a realização de nossa tradução do documento. $N$ do $A$.

${ }^{2} C f$. GALLUS, Anonymus. Op. cit. p. 138.

${ }^{3}$ Unde quia spes in eo iuvenis bone indolis pullulabat iamque magnum in eo glorie signum militaris apparebat. (id.). T.A.

${ }^{4}$ Utilizaremos esta sigla para abreviar Gesta principum Polonorum. $N$ do A.

${ }^{5}$ Respondebo bella regum atque ducum non euuangelium me scripsisse. (GALLUS, Anonymus. Op cit. p. 212). T.A. 
Os trabalhos sobre a estrutura da Sociedade Medieval mostram que a sua construção passa por uma teoria da divisão das funções, visto que as sociedades tendem a distribuir as obrigações entre os seus membros. Um dos marcos da procura pela essência dessa segmentação no medievo vem da "clássica" pesquisa de Georges Duby, a qual resultou no livro as Três Ordens ${ }^{6}$. Esta obra apresenta o corpo social na época medieval teorizado em uma tríade de funções. Essa divisão teve seu eco da estrutura indo-européia, a qual é conhecida cientificamente graças aos trabalhos de Georges Dumézil. A teorização tem suas origens em um princípio que muitos consideram a do equilíbrio: três são as ordens no medievo; três são as formas de Deus; três são as formas, portanto, necessárias para o equilíbrio. A necessidade do equilíbrio passa, em nossa perspectiva, como um dos pontos fundamentais para que as ordens fossem pensadas, transformando assim os elementos da tripartite da sociedade em um instrumento teórico para o desenvolvimento de um poder concreto. A produção de idéias, como a da divisão das funções, mostra que a Idade Média produz teorias de gestão sócio-política. Orar, lutar e trabalhar são as obrigações principais da ideologia funcional européia no medievo latino. A escrita da trifuncionalidade tem seu marco com os textos eclesiásticos no século $\mathrm{X}$. A sua retomada é importante para termos um apanhado geral sobre como a teorização da sociedade conecta a guerra a todo o aparato administrativo, político e, podemos dizer, religioso.

Quando as proposições de Gerardo de Cambrai e Adalberto de Laon tornam-se, nos séculos X e XI, a forma textual dessas teorias, fazem com que estes escritos clericais sejam as diretrizes da autoridade, as quais vão forjar os parâmetros do poder Medieval. A discussão da autoridade vai ganhar mais um capítulo de sua história durante as disputas Papais e Imperiais do século XII. Cada uma das ordens começa a procurar ter inserção dentro das demais. $\mathrm{O}$ mundo guerreiro é atacado pelos teóricos clericais, fundando, assim, a

${ }^{6}$ DUBY, G. As três ordens ou o imaginário do feudalismo. Lisboa: Editorial Estampa, 1994. 
discussão que produziu padrões de aceitação para os poderes locais. $\mathrm{O}$ espiritual e o guerreiro andam juntos nas figuras de autoridade européias, graças à tentativa de organização dos clérigos do grupo guerreiro, organização que tem como primeiro motor a própria proteção das instituições religiosas. A proteção passa pela "racionalização" da atividade guerreira: ensina-se ao laico como e quando a força pode ser usada. A guerra recebe definições como: tipos de inimigos e períodos em que se pode investir no combate. A guerra justa, tema tão agradável aos romanos, tem um renascimento durante o embate das ordens. Fazer guerra justa é uma virtude, a qual auxiliará uma parte dessa sociedade na utilização desse princípio em proveito próprio.

Como em toda divisão, mesmo que tenha a finalidade de equilibrar, existe sempre a tendência de hierarquizar, ou melhor, de conceder a uma das partes certo direito a mais de autoridade. Politicamente, a trifuncionalidade produziu um vasto debate sobre qual ordem era a autoridade sobre a sociedade. Os Laboratores ficaram em uma situação de inferioridade e tal condição em alguns séculos se transformará em desafeto, gerando mudanças nessa ordem. Porém, as duas ordens que mais nos interessam são as dos Oratores e Bellatores, pois suas discussões conduzirão o raciocínio que os círculos reais criarão sobre sua função. Apesar de uma série de escritos que tentam colocar o guerreiro sob a guarda do clérigo, o Bellator tem sua figura modelada em um indivíduo protetor dos demais, situação causada pela necessidade eclesiástica de proteção, que acaba sendo revertida para o próprio grupo guerreiro.

Oratores trabalharam muito para incorporar sua importância junto aos guerreiros, tentando, ao mesmo tempo, ganhar sua proteção e evitar que a violência deles prejudicasse a sua ordem. A violência permanece durante a Idade Média em grande parte como o fundamento das hierarquias de poderes ${ }^{7}$. A legitimidade da posição de um soberano depende em muito de seus feitos militares, que podem

${ }^{7}$ LE GOFF, J.; SCHIMITT, J.-C. Dicionário temático do ocidente medieval. Bauru: EDUSC, 2002. p. 610. 
ser considerados símbolos de uma prática que efetivamente dá ao rei, ao nobre ou ao cavaleiro o status de legítimo. Os Oratores passam a necessitar desviar as ações de violência, criando assim regras que normatizam o ato do Bellator, o que cria mais uma série de elementos que tornam a ação bélica legítima. As práticas da guerra são, no medievo, lembradas pelo seu personagem mais ilustre: o cavaleiro um personagem que se forma a partir da criação de uma instituição, a qual vai ganhar contornos próprios em um tempo curto. Isso produz nas discussões sobre sua prática uma tendência a que os poderes laicos acabassem imitando os preceitos da ordem dos clérigos ou, ao menos, apresentassem alguma característica que servisse de argumentação para a solidificação de uma hegemonia ou ideologia por parte daqueles que querem ter autoridade ou respeito em um círculo social. Das bases guerreiras a figura do rei recebe uma das qualidades mais importantes, em nossa perspectiva, para a consolidação de sua figura entre os pares da sociedade política em que vive. O rei torna-se o protetor - que tem a virtude do guerreiro -, sendo, assim, capaz de realizar em armas a sua função, a qual é intrínseca à sua personalidade, graças à sua ligação direta com a divindade.

O rei medieval receberá em seu atributo a virtude da glória e da vitória. Sua denominação passa pela eficiência militar: a vitória no campo de batalha fomentará a argumentação de sua "superioridade" em relação aos demais membros de sua sociedade política. Em nosso trabalho estamos procurando a figura do rei legítimo. O rei que não possui as armas perde uma parte importante de sua veracidade como cabeça do grupo e sua efetividade sobre outros grupos também é afetada. Se sua imagem não for ligada à belicosidade, seu ofício não se torna inteligível aos demais. A guerra não é apenas uma ação, ela é também constituída pela memória. Ouvir sobre batalhas faz parte da instrução no mundo clássico e, como conseqüência, a aristocracia medieval terá em seu imaginário a necessidade da aparição da guerra, não como um flagelo, mas como o momento em que ocorre a conciliação entre os favores da graça de Deus e a correta utilização 
dos preceitos de soberania: a supremacia do monarca em ser o árbitro, bem como o protetor e, talvez o mais importante, o libertador da comunidade, o transformava no representante capaz de fazer na terra o que é correto em relação ao divino. No campo de batalha esses ofícios dos reis tornam-se plenos.

O rei inicia sua aparição nos textos medievais como sendo esse personagem do herói mortal, que na adversidade demonstra todo o seu empenho e predestinação para conferir segurança ao mundo cristão e, talvez mais importante, cuidar de seu grupo. O cronista medieval tem a preocupação de fundar o guerreiro em seus textos, pelo fato de que seu comitente tem a perspectiva de que sua história deve apresentá-lo como guerreiro. A paz é obtida na guerra e isso também mostra os motivos pelos quais as batalhas devem fazer parte do corpo dos textos régios. A guerra é um elemento "burocrático". A conquista pela batalha honrada cria legitimidade do ganhador sobre o perdedor no confronto. Quando revista em texto dinástico, a vitória passa a ser, em nossa perspectiva, um ganho "eterno". Ao mostrar a linhagem como guerreira, o escritor dá ao seu patrocinador direto os ganhos de todos os seus antecessores. Como nossa fonte é uma crônica, temos que observar todos os elementos que possam servir de ligação entre o presente da escrita e o passado reconstruído. A herança militar desempenha uma função no texto de Galo Anônimo: a de refazer na figura dos primeiros reis uma situação de equilíbrio, prosperidade e paz. Essa situação é abalada na metade do século XI pelo levante dos pequenos grupos eslavos que tinham na figura de Bolesław I um elemento de união, símbolo esse que não resiste aos princípios eslavos da sucessão por aclamação. Seus descendentes tiveram que demonstrar que estavam à sua altura nas virtudes, ações e poderes.

O início do texto do monge apresenta o descendente mítico dos Piastes, Siemowit - o qual teria substituído a família dos Pumpils pelo fato de estes não terem a predestinação que os pais de Siemowit 
receberam em uma "noite de tosa" contrato entre a família real e Deus. O príncipe, como coloca Galo Anônimo, "Siemowit tendo ascendido ao poder não empregou sua juventude em prazeres ou em veleidades, mas por seus esforços e coragem marcial ganhou fama e a glória da honra e estendeu os limites do reino a espaços nunca antes obtidos por ninguém"9. A vitória militar é uma das heranças do sangue dos Piastes. Os primeiros reis, que não tiveram problemas marcantes e realizaram as ações de expansão, são lembrados pelo autor para reforçar a legitimidade do rei contemporâneo. A virtude militar é a virtude dos Impérios, quando lembrado por qualquer grupo o próprio mundo Romano é citado como "O Império Romano", ou seja, tem uma conotação de ação de força bélica.

O Império Romano, quando retomado na Idade Média pelo desenvolvimento do Império Germânico dos otonidas, traz em sua figura a vitória militar. Virtudes como a glória, a figura do rei como um elemento totalmente nobre e até o imaginário da Dei Gratia, que inflama a situação de predestinação dos reis, têm de utilizar a guerra como um elemento de legitimação, não somente para os fins práticos, mas também teóricos. A violência fez a Idade Média parecer um "teatro de uma violência endêmica e sem limites, verdadeiro

\footnotetext{
${ }^{8}$ A tosa seria uma apresentação do filho à comunidade, um ritual de iniciação pagão da região. O batizado de Siemowit, filho de camponeses pobres e humildes, aconteceria no mesmo momento da do filho do Duque Pumpil. O primeiro livro narra nesse momento a chegada de dois estranhos que entram na cidadela e tentam participar do banquete do duque, porém, tendo ele os afugentados, acabam sendo recebidos por Chościsko, pai de Siemowit. Por receber esses dois estranhos e oferecer-lhes o pouco que tinha, a família Piaste teria um destino traçado pela divina providência de Deus, mesmo sendo pagãos os pais do futuro rei. A predestinação começa aqui, o autor dá ênfase até ao fato de que não devemos falar dos feitos dos Pumpils, pois estes não estavam dentro dos planos de Deus. $N d o \mathrm{~A}$.

${ }^{9}$ Semouth vero principatum adeptus non voluptuose vel inepte iuventutem suam exercuit, sed usu laboris et militie probitatis famam et honoris gloriam acquisivit, atque sui principatus fines uterius quam aliquis antea dilatavit. (GALLUS, Anonymus. Op. cit. p.25). T.A.
} 
contraponto à ordem jurídica moderna"10 . Porém, essa "violência" é parte integrante da prática social e jurídica. A evolução da guerra, como indica Franco Cardini, a fez transformar-se num elemento guardado por instituições. Primeiramente, um conjunto de milites, que vai tomando a forma da monarquia e, dentro de suas instituições, se transforma de grupo de cavaleiros em uma corte real, vai à guerra, fixando-se, com isso, como um parâmetro para a autoridade legítima, o que torna a belicosidade um instrumento de privilégio aristocrático a serviço público ${ }^{11}$.

O pretendente à autoridade deve construir a sua obrigação militar no imaginário social de seu grupo político, pois somente com a cristalização de sua obrigação ele consegue ter direito e privilégio perante aquela facção da comunidade. Por isso, a guerra tem tão grande importância nos textos dinásticos na Idade Média. O ótimo guerreiro pode defender sua comunidade e, tendo essa obrigação, pode ter o "monopólio" das atividades jurídicas e ganhar talvez um dos atributos mais importantes para o período: a autoridade conseguida e legitimada pela tradição. A guerra justa pode ser feita por aquele com maior capacidade de ação, o que traz a possibilidade de o elemento que tem essa capacidade qualificar sua ação como justa. Ele pode também manter e expandir sua hegemonia social com certa facilidade. Porém, ele necessita expor suas qualidades de forma correta. A Idade Média apresenta uma figura que vai ganhar destaque na construção do imaginário do rei justo, o qual possui e pode realizar todas as tarefas administrativas políticas que quiser, por ser um elemento diferenciado em sua comunidade. Utilizaremos a expressão "Homens de saber" para designar os escritores e teóricos régios desse período, pelo fato de que parece mais certo pensar em uma pessoa que conhece a maneira de escrever e tem noção de como articular as

10 SILVA, M. C. da. Autoridade pública e violência no período Merovíngio: Gregório de Tours e as Bellas Civilia. In: Instituições, Poderes e Jurisdições. Curitiba: Juruá, 2007. p. 181. T.A.

${ }^{11}$ LE GOFF, J.; SCHIMITT, J.-C. Op. cit. p. 473. 
figuras e descrições com as necessidades políticas pedidas por seu comitente.

O "homem de saber" tem grande importância na elaboração da tradição que serve ao político. A sua arte de trabalhar a história de um grupo social faz dele o elemento que consegue produzir o ambiente para que a autoridade floresça dentro do imaginário social. Vemos que muito do que a historiografia polonesa tem a respeito dos reis guerreiros dos primeiros anos da região é fruto dos textos de Galo Anônimo. Ele reproduz na figura histórica de Mieszko I e Bolesław I a era de ouro que, segundo o autor, tem seu fim exatamente com a morte de Bolesław, ou como ele diz: "Assim, retirando-se o rei Bolesław da morada mundana, à era de ouro sucedeu uma era de chumbo" ". A paz é rompida, porque os reis seguintes a esse tempo de glória são indivíduos que o autor apresenta como tendo perdido a aliança com Deus por não terem ou não praticarem as virtudes que os primeiros Piastes possuíam. O grande momento em que o grupo tribal conseguiu estender os Piastes até o Báltico fica perdido na história, como canta o poema da morte do rei: "Ah Bolesław Ah Bolesław, onde está toda a sua glória?"13. Ao remontar aos feitos destes dois primeiros reis, Galo Anônimo solidificou sua imagem para a posteridade, mesmo além do medievo. Mas, é exatamente dentro de seu período que o autor mostra sua capacidade de eficiência ideológica.

As duas figuras são perfeitamente construídas para que no final de sua narração Bolesław III recupere todas as virtudes e glórias sumidas no final da vida de seu tataravô, mostrando, junto com a fundação das tradições, que os Piastes tinham eficiência militar. Era ele totalmente completo e devidamente instruído na arte da guerra, sem mencionar que era também divinamente agraciado com as virtudes que somente os primeiros Piastes - os quais ainda estavam envoltos em uma aura de lenda - e o patrocinador da $G p P$ poderiam

\footnotetext{
12 Bolezlauo igitur rege de mundana conversatione decetente, etas aurea in plumbeam est conversa. (GALLUS, Anonymus. Op. cit. p.68). T.A.

${ }^{13}$ Heu, Heu Bolezlaue, ubi tua gloria. (Ibid., p. 70). T.A.
} 
ter. Serão os textos dos "homens de saber" que ajudarão a modificar regras e aspectos sociais. Porém, esses textos não pertenciam propriamente aos "homens de saber", pois, como coloca Jacques Verger, pessoas como Galo Anônimo estavam "servindo um mestre indivíduo ou coletividade, de providenciar ou aplicar as decisões ou regulamentações aqueles que eram, verdadeiramente falando, os detentores do poder" ${ }^{\prime 4}$. A pena dos autores trabalhava de acordo com a necessidade. A glória militar era uma necessidade impossível de não ser abordada pelo monge.

A glória militar ensaia um retorno em figuras mais carismáticas, mas elas possuem sempre pequenos defeitos: Mieszko II não tinha a mesma qualidade, por isso foi surpreendido pelos Bohemios ${ }^{15}$; Kazimierz, o Grande, realiza muitas ações militares e consegue recuperar uma parte da hegemonia dos Piastes, mas ele não era completo, pois tinha a formação de monge, não sendo um guerreiro pleno ${ }^{16}$; Bolesław II tem perfil de guerreiro e quase consegue igualar seu homônimo antepassado, mas não possui temperança, por isso perde o poder. $\mathrm{O}$ rei tem de ter o controle das emoções. Alguém descrito como quem não controla suas emoções é visto como alguém que não consegue manter suas obrigações. $\mathrm{O}$ fato de representá-lo como incompatível com o ofício militar régio e não tendo virtudes é uma artimanha do autor para preparar a queda do tio de Bolesław III, que passou por uma "conspiração" contra seu poder. O mesmo ocorre para amenizá-la: ele acabou por assassinar um bispo, o que manchou a história piaste interna e externamente. Por isso, as suas qualidades são restringidas e sua história é contada de uma forma rápida. Todos os reis que antecederam Bolesław III no trono têm suas histórias recriadas. O texto inteiro é montado para a "ressurreição" do rei piaste na figura do comitente de Galo Anônimo.

A autoridade pode ser exercida plenamente a partir dele, pois este é o Piaste que possui aquilo que faltou para que a providência

\footnotetext{
${ }^{14}$ VERGER, J. Homens e saber na Idade Média. Bauru: Edusc, 1999. p.169.

${ }^{15}$ GALLUS, Anonymus. Op. cit. p.75.

${ }^{16}$ Ibid., p. 78 .
} 
divina retornasse à terra polana. Em seu capítulo II, que apresenta "as profecias sobre Bolesław", ele mostra como dentro do círculo de cavaleiros o garoto venceu os Cumanos em uma batalha em que Deus "revelou" a cavalaria àquele jovem, o que é visto pelos membros do conselho de guerreiros como uma benção. Além dessa colocação, o que os guerreiros olham no menino é que: "já as façanhas de sua juventude provam que a Polônia um dia será devolvida por ele ao seu estado primevo" $" 17$. Os pares militares são as vozes da legitimidade da figura guerreira do rei piaste. A utilização de "vozes" dotadas de legitimidade é uma estratégia do autor, que poderemos observar em outras "faces" da figura do rei de Galo Anônimo. Aquele que tem autoridade ou uma posição usa a profecia - seja ela dita pelo Imperador, por um soldado ou ainda por um ancião - como um veículo para persuadir o leitor ou ouvinte da crônica de que os Piastes tinham uma aura de superioridade na comunidade. A autoridade parece necessitar que outra autoridade reconheça a sua capacidade e em alguns casos a igualdade de forças.

A autoridade não é exclusividade de uma pessoa, mas de um grupo. A figura do rei guerreiro piaste é feita não somente pela pessoa do rei, mas por todo um círculo que quer manter sua posição e, para isso, deve convencer outros de sua condição. As ordens batalharão para criar sua posição. Porém, cada grupo menor vai tentar utilizar um pouco do que cada uma dessas ordens produziu para desenvolver seu poder. O rei medieval cristão latino nasce nessa "batalha das ordens" e "apropriação de saberes" pelos grupos locais. Sua figura é considerada como uma novidade, sendo um elemento que tem a tendência a deter o officium do equilíbrio, passando a ser um Bellator. Os Piastes querem ter o privilégio da autoridade, por isso a sua crônica tem um grande volume de narrações de batalhas, pois sem elas seu texto seria estéril para a finalidade que a obra tinha. O grupo de Bolesław III utiliza o imaginário do guerreiro para seus fins, não sendo uma manipulação total, pois sabemos que existe a crença no rei

\footnotetext{
${ }^{17}$ Quia iam in factis eius puerilibus comprobatur, quod Polonia quandoque per eum in statum pristinum. (Ibid., p.156). T.A.
} 
guerreiro. As teorias têm de criar uma perspectiva que se compõe em uma realidade concreta, em muitas vezes, não criticável, mas com a possibilidade de que uma necessidade tente redimensionar ou alterar uma parte desse todo por meio dos instrumentos culturais disponíveis nas relações humanas firmadas entre os grupos de uma área.

As virtudes - tais como a fortitudo ${ }^{18}$, que é uma das quatro virtudes cardinais - são recorrentes nos Piastes. A maneira pela qual a fortitudo aparece se aparenta muito com a maneira por que Saxo Grammaticus a mostra em seu texto quando faz referência a Skyoldus, o qual inicia a sua virtude na infância, matando um urso ${ }^{19}$. O cronista polano utiliza a mesma figura cênica para introduzir o personagem de seu comitente. Bolesław, na infância, é retratado em dois capítulos, que parecem, em uma primeira leitura, mais uma recorrência da necessidade de mostrar a vida do personagem piaste. Porém, destacamos os trechos nos quais o jovem Bolesław III aparece combatendo um urso e um javali. Esses trechos mostram a fortitudo de seu patrocinador, como alguém que é mais completo do que seus ancestrais, pois na sua infância apenas se interessava por atividades que mostravam que sua personalidade não era como a de um jovem comum. O personagem mais importante da obra é o único a ter a aparição desse elemento. $\mathrm{O}$ rei guerreiro tem qualidades presentes em sua família, mas elementos como a fortitudo são exclusivos de um indivíduo, o qual tem a posição de ser um "clímax" da história polana.

\section{3 - A crônica e a guerra}

O gênero cronístico nasce diretamente a partir de um gênero distinto: a cronografia, que, a partir dos textos de São Jerônimo, nos

\footnotetext{
18 "Força" ou "coragem", podendo significar também "força de alma", "bravura", "firmeza", "decisão", "ardor", "intrepidez", "energia". N do A.

19 MUCENIECKS SZCZWALINSKI, A. Virtude e conselho na pena de Saxo Grammaticus (XII-XIII). Dissertação. Curitiba: Universidade Federal do Paraná, 2008. p. 70.
} 
quais os elementos históricos começam a ganhar mais importância, como na sua obra De viris Illustribus, moldará a maneira de se pensar a produção das cronologias na Idade Média. Nas páginas dos primeiros cronistas começa a existir uma convicção de que o Império havia sido criado por Deus para preparar o advento de Cristo. Assim, a Cristandade ganha muito mais força nas linhas dos primeiros cronistas ocidentais. As instituições passam a ser parte integrante do discurso dos textos cronísticos, talvez pelo fato de seus autores fazerem parte delas ou de sua figura ser algo impossível de não ser citado daquele momento em diante. A história universal começa, a partir de Próspero de Aquitânia, a incorporar a regionalização, assim como temos obras que passam a trazer uma recapitulação da "História do Mundo" para explicar algum fato encomendado nos textos de crônica durante a Idade Média ${ }^{20}$. Outro fator que as crônicas herdam dos pioneiros da cronologia é a apologia. A utilização dos textos do início do mundo tardo-antigo para divulgar o Cristianismo fez seu eco no mundo medieval, pois, para introduzir uma doutrina ou uma ideologia régia, os autores seguem em muito a maneira como os primeiros cristãos faziam em seus textos universais para explicar a nova religião e os novos poderes, dentro de uma sociedade que tem na tradição uma base sólida de seu pensamento. A apologia a um ideal tem ressonância dos textos cristãos primitivos. A função da crônica como instrumento apologético existe em nossa fonte. As origens parecem servir, no texto do monge, para edificar uma tradição, que é confeccionada de maneira a não parecer algo recente.

Destacamos, porém, que o regionalismo tem mais efeito do que o universalismo. O fato de que o autor está em uma região a qual não possui uma tradição evidente no mundo cristão o faz evitar as ligações muito recuadas no tempo. A construção do passado piaste não remete a períodos muito recuados, o máximo que o autor faz é remontar ao momento da divinização de seu ancestral Siemowit. A sua concentração no corpo da dinastia parece ter fundamento na

20 SANCHEZ GALÁN, P. J. El género historiográfico de la Chronica. Cácer: Universidade de Extremadura, 1994. p. 52. 
posição de que o autor deve apenas falar da dinastia e da seqüência de parentes que se ligam a Bolesław. Assim, o universalismo seria um fator pelo qual o autor não se interessava. $\mathrm{O}$ mundo Polano era persuadido a crer que os Piastes eram as raízes da sociedade cristã latina, ou seja, a preocupação do texto está em atrelar a fundação do mundo cristão latino na região à figura da família de Bolesław, tendo os primeiros membros da dinastia uma "predestinação", que foi somente confirmada com o casamento e o batizado, dentro dos costumes cristãos, de Mieszko I. A partir dele um elemento importante é apresentado conjuntamente com os Piastes: o Imperador Germânico.

O momento de Galo Anônimo é o período em que ocorrem os embates entre o Império Romano Germânico e o Papado. Em 1073, Gregório VII inicia um período de afirmação teórica da supremacia do pontífice romano, após um período em que o poder temporal se construiu com os reis, como Carlos Magno. A estruturação do papa como um poder transcendental que guia essa sociedade cristã faz espalhar o pensamento que concebe a sociedade como um organismo ordenado segundo os desígnios de seu Criador ${ }^{21}$. Tal proposta faz essas duas instituições entrarem em uma disputa intelectual sobre quem possui uma autoridade sobre a sociedade. Isso criou uma série de tratados que a historiografia medieval conhece por versar sobre a incumbência e delimitação dos poderes e jurisdições de cada uma destas entidades - discussões que inflamaram o cenário político medieval, mas não ficaram apenas no âmbito de suas paragens. Essa discussão foi importante para as monarquias conceberem algo de sua própria instituição. Os argumentos do Império Germânico serviram para florescer a posição dos ofícios régios, os quais se espelham nas explicações do poder universal do Imperador. Os polanos criam as linhas gerais para sua monarquia também por meio do aproveitamento das teorias construídas nesse contexto. Os momentos

${ }^{21}$ SOUZA, J. A. de C. R.; BARBOSA, J. M. O reino de Deus e o reino dos homens. Porto Alegre: EDIPUCS, 1997. p. 28. 
de discussão teórica entre os poderes criam a argumentação dos Piastes contra o Império Germânico.

Os discursos dos papas contra os Imperadores são as bases para os discursos dos Piastes contra os Imperadores Germânicos, principalmente Henrique IV. A aproximação dos Piastes a Roma foi acelerada logo após a morte de Otão III, pois seus sucessores boicotaram os ganhos jurídicos do poder polano em construção. A Igreja era, graças a sua disputa com o Império, uma maneira de o poder piaste afastar a sombra de seu inimigo laico, aproveitando os argumentos da instituição clerical que depreciavam os Imperadores. Podemos observar isso nas passagens, como a do último livro da crônica, em que ele utiliza a posição de descrédito de Henrique IV junto a Roma para valorizar Bolesław III. Neste capítulo, o autor relembra, por meio da leitura de uma carta do rei a Henrique, que este não tinha virtudes e nem protegia a Igreja romana. Os discursos papais e imperiais são utilizados por Galo Anônimo para construir a dinastia piaste, que inicia com Mieszko sua trajetória, indo até o século XII.

Mieszko é um rei considerado "histórico", pois possui registros em outros documentos medievais, sendo sua figura associada à do rei cristão. $\mathrm{O}$ monge edifica a figura do rei a partir de uma perspectiva mítica. Os atributos da guerra ainda não ficam evidentes na construção desse ator do teatro de Galo. O foco principal do autor é, no primeiro livro, Bolesław I, homônimo de seu comitente, o que podemos levar em conta como uma estratégia de construção da obra, pois eleva dois reis homônimos, fazendo assim uma analogia entre o passado e presente do reino. A força militar entra em cena na crônica a partir do instante em que Bolesław I encontra o Imperador Otão III. A troca de presentes entre os dois é destacada, afinal ocorre: "E como insígnia triunfal deu-lhe como presente uma das unhas da cruz de Nosso Senhor com a lança de 
Santo Maurício, e devolveu Bolesław um braço de Santo Adalberto" $" 22$.

A crônica evidencia em sua construção a figura militar e os artefatos que lembram essa atividade. A entrega da lança de Santo Maurício está inserida no momento em que o Imperador dá a Bolesław a coroação e o título de "amigo e aliado do povo romano" 23 e, ao mesmo tempo: "garantiu-lhe sua autoridade sobre qualquer honra eclesiástica pertencente ao Império em qualquer parte do reino da Polônia ou outro território conquistado ou que possa ser conquistado entre os bárbaros" ${ }^{24}$. A lembrança de que os Piastes tinham o direito sobre a administração dos territórios conquistados e, principalmente entre os bárbaros, mostra como as idéias apologéticas de fundação são construídas: os direitos nascem nos primeiros reis e são corroídos até o presente de Galo Anônimo. A cronologia dos direitos do rei é devidamente apresentada. A guerra é uma qualidade que existe no passado e que sofre baixas, mas renasce em Bolesław III, pois até as tropas imperiais admiram sua condição de guerra, como coloca em seu poema contra o Imperador Henrique IV: "O que seria, se ele sempre usasse toda a sua força: Nunca irá o Imperador prevalecer contra ele na luta!". ${ }^{25}$

A comparação militar na crônica parece um atributo apologético quando dá à figura régia de Bolesław condições iguais ou superiores ao do poder imperial no campo de batalha, o que era um recurso eficiente para doutrinar um dos receptores dessa fonte: o círculo guerreiro, o local onde a nobreza primária dos polanos se concentrava. Galo Anônimo enfatiza até a leitura de sua obra nas

\footnotetext{
${ }^{22}$ Et pro vexillo triumphali clavum ei de cruce Domini cum lancea sancti Mauritii dono dedit, pro quibus illi Bolezlauus sancti Adalberti brachium redonavit. (GALLUS, Anonymus. Op. cit. p.36). T.A.

${ }^{23}$ Et populi Romani amicum et socium appellavit. (id.). T.A.

${ }^{24}$ Insuper etiam in ecclesiasticis honoribus quicquid ad imperium pertinebat in regno Polonorum, vel in aliis superatis ab eo vel superandis regionibus barbarorum, sue suorquem sucessorum potestai concessit. (Ibid., p 39). T.A.

${ }^{25}$ Qui, si forte suos omnes simul congregavit. (GALLUS, Anonymus. Op. cit. p. 242). T.A.
} 
"escolas e palácios", veremos essa comparação em outros tópicos dessa pesquisa. Pois, a comparação ao poder temporal do Imperador, o qual era o mais evidente do século XII, representava a possibilidade de legitimação dos Piastes como poder laico central do território polano, o qual era, como veremos, formado por vários ducados menores. Aproximar da ordem dos guerreiros a figura régia dá uma característica para essa figura antiga, uma novidade no medievo, pois ganha adaptações vindas da cristandade, das quais a mais marcante é o fato de ter tanto a graça de Deus como a vitória militar ${ }^{26}$. As qualidades são importantes para solidificar o guerreiro, o imperador que Galo Anônimo retrata é exatamente Henrique IV, imperador que passa por sérias crises com a cristandade e com o Papado. $\mathrm{O}$ autor instiga o leitor a lembrar dessa situação, mostrando por via da transcrição de cartas a falta de honra do Imperador. O monge pode fazer essa colocação no texto para reforçar as qualidades de seu comitente. As qualidades têm destaque, pois com elas o indivíduo pode, com veracidade, construir uma posição de superioridade no seio da sociedade política de que faz parte.

Em seu texto, Galo Anônimo enfatiza os feitos dos reis quando inicia o livro III de sua obra com: "Assim como os homens santos são celebrados pelos seus bons atos e milagres, os reis e os príncipes deste mundo são exaltados no triunfo das guerras e das vitórias" $^{27}$.

Por isso, vamos apresentar as virtudes que as descrições de guerra do autor apresentam, uma vez que bravura, temperança, coragem, honra são atributos indispensáveis ao monarca desde a época clássica e helenística. O bellator régio é uma figura diferenciada, pois tem de conseguir vitórias no campo das ações e criar sua imagem vitoriosa nos combates. A figura do rei guerreiro ganha as páginas das primeiras canções de gesta francesas. O rei

\footnotetext{
${ }^{26}$ LE GOFF, J.; SCHIMITT, J.-C. Op. cit. p.398.

${ }^{27}$ Nam sicut sancti viri bonis operibus et miraculis celebratur, ita mundani reges et principes bellis triumphalibus e victoriis sublimatur. (GALLUS, Anonymus. $O p$. cit.p. 212). T.A.
} 
começa sua jornada de imortalização no imaginário e prática política do período em cerca de 80 a 100 poemas épicos, a maioria versando sobre o rei Carlos Magno. Essa literatura, dominada por preocupações feudais e aristocráticas, narra as façanhas guerreiras dos grandes barões merovíngios e carolíngios. Sendo a literatura secular em latim, ficou largamente confiada a assuntos derivados, diretamente ou indiretamente, de modelos clássicos ${ }^{28}$.

O texto medieval recebe influência dos clássicos até construir, por volta do século XII, novos mecanismos de soberania. Estes mecanismos se apoiam em escritos que mesclam os pensamentos clerical, clássico e a ideologia local em um novo formato da aristocracia laica, a qual cria uma literatura preocupada em apresentar as genealogias nobiliárquicas, compondo as canções de gesta. $\mathrm{O}$ texto da $G p P$ é parte integrante dessa troca cultural entre a terra dos Polanos e as áreas de produção cronística, como é a de Galo Anônimo $^{29}$ :

O texto medieval tem de ser visto como algo que o leitor veria no conteúdo dos livros que lia não como uma expressão da personalidade e uma opinião de outro homem. Ele via os textos como parte deste grande e total corpo do conhecimento, a scientia de omni scibili, a qual uma vez fora propriedade das antigas sagas. Contudo, lia em um venerável livro antigo não tomando ele como sendo a afirmação de alguém, mas um pequeno pedaço do saber adquirido por alguém há muito tempo atrás de alguém ainda mais antigo. ${ }^{30}$.

A meta do autor é também fazer com que seu texto seja parte do "conhecimento", mesmo sendo algo regional. Os seus escritos são por nós vistos como montagens, mas para seus contemporâneos são exemplos verdadeiros de condições reais, fontes da verdadeira realidade para seus leitores.

${ }^{28}$ LOYN, H. G. Dicionário da Idade Média. Rio de janeiro: Jorge Zahar, 1997. p. 237.

${ }^{29}$ A sua procedência é indicada na fonte no prefácio do primeiro livro quando relembra a Provença e o mosteiro de St. Gilles. $N$ do $A$.

${ }^{30}$ BOULHOSA, P. P. Sagas Islandesas como fonte de história da Escandinávia medieval. Signum, Porto Alegre, n. 7, 2005. p.25. 


\section{4- As virtudes da guerra}

A latinização é propagada, sobretudo, pela via literária. Os textos deveriam trazer o que se deseja apresentar dentro de uma argumentação consistente - esse meio de divulgação tem nos clássicos sua gênese. Apresentar o "melhor meio de governo" ou o "rei perfeito" tem suas raízes em textos mais recuados no tempo. $\mathrm{Na}$ Idade Média essa lógica parece não se perder: mostrar a melhor forma de governo passa por incorporar as virtudes conhecidas às figuras ou personagens das crônicas. Por isso, Galo Anônimo mergulha sua obra no mar das virtudes mais comuns e mais aceitas da política clássica para assegurar que a latinidade de sua área não esqueça os seus primeiros nobres. A $G p P$ quer fazer com que os eslavos acreditem que o rei polano piaste pode fazer a condução da política local. As virtudes, por isso, são importantes. Em nossa perspectiva de análise da hierarquização social proposta pelos Piastes, elas representam um instrumento de argumentação indispensável para a Crônica de Galo Anônimo: "Pois, Bolesław [I] elevou-se até esta glória e dignidade por seu senso de justiça e equidade, virtudes as quais desde o início desenvolveram o poder e o império dos Romanos" ${ }^{31}$. O primeiro Piaste coroado consegue edificar virtudes que lhe possibilitarão expandir a sua hegemonia. Os Piastes parecem poder conduzir sua força como os romanos o fizeram.

As canções, crônicas e demais textos régios são os escritos históricos que relembram batalhas, ou melhor, relembram atitudes perante a guerra, atitudes que corroboram a necessidade de um grupo que se espelha em um indivíduo, produzindo pela escrita de seus feitos a incorporação da guerra. Esta é um momento interessante, pois nela temos a junção, nos textos, de duas virtudes caras ao mundo clássico: gloria e honor. Duas virtudes que, como coloca Maria

\footnotetext{
${ }^{31}$ Iustitia nimirum et equitate ad hanc Bolezlauus gloriam et dignitatem ascendit, quibus virtutibus initio potentia Romanorum et imperium excrevit. (GALLUS, Anonymus. Op. cit. p.50). T.A.
} 
Helena da Rocha Pereira, estão ligadas à res publica, isto é, à sociedade política. Quando a autora cita Cícero, em Dos Deveres, vemos o motivo de o texto colocar a gloria nas passagens de guerra. Pois, se a glória precisa de três condições para ocorrer - "ser amado pela multidão; ter a sua confiança; ser admirado e digno de honrarias" ${ }^{, 32}$-, criar a admiração por meio das virtudes clássicas mais amplas e que remetem à guerra faz da tópica do guerreiro um artifício que lembra em muito os romances arturianos, criados durante os séculos XII/XIII e que revestem os heróis das virtudes e dos objetos monárquicos e destinam-lhes um lugar que só aos reis cabia no seio da sociedade ${ }^{33}$. Os romances arturianos serviram em grande parte para educar a nobreza régia na cristandade. A figura do rei como exemplo é adotado pelo monge, que, ao invés de remontar a um rei que tivesse sua imagem mais enraizada no imaginário, deve transformar os Piastes no personagem instrutor da Cristandade local, não somente como um exemplo, mas também para fundar o respeito e a necessidade dessa casa real nos círculos mais elevados da autoridade. Arthur pode ter sido a leitura que Galo Anônimo teve em seus anos de instrução na Provença, mas a nobreza local tem de ler no lugar de Arthur o nome dos Piastes.

Assim, nossa idéia é que os Piastes, como o modelo de educação para a sociedade, devem ser adotados pelo motivo de a região Polana ser composta de vários pequenos ducados. Essa situação faz necessário edificar, via o texto da $G p P$, uma posição superior dos reis piastes sobre seus pares, fazendo, assim, do ducado piaste uma monarquia que deve servir de exemplo, estimulando, dessa forma, a obediência e manutenção dos direitos da dinastia. Pois, sendo estes os elementos que conseguem fazer parte da educação,

\footnotetext{
32 PEREIRA, M. H. da R. Estudos de história da cultura clássica. Lisboa: 1993. p. 345-347.

${ }^{33}$ PEREIRA, R. de C. M. Representações da Realeza nas fontes históricas e literárias da Idade Média em Portugal. In: ANDRADE FILHO, R. de O. (Org.). Relações de Poder, Educação e cultura na Antigüidade e Idade Média. Rio de Janeiro: Editora Solis, 2005. p. 105.
} 
teriam uma posição superior na comunidade. Os Piastes tentam ser o pilar dessa instrução da nobreza para evitar o levante ou mesmo a fixação de algum paladino em seu lugar. A função do rei é tardio na terra polana, pois é por volta do século XI que a monarquia latina começa a substituir o sistema tribal de governo. Então, os Piastes são lembrados como exemplos comparáveis a qualquer figura que possa ser edificante a seus pares para que estes sigam, no momento da institucionalização do sistema monárquico na região, a casa que tem sua origem na família de Mieszko I e não a de algum paladino do século XII.

O rei piaste usa a figura de sua pessoa e de seus antecessores para produzir o efeito de educação que visava à incorporação dos Piastes como base do poder. Os feitos militares moldavam a "res gesta" quando colocavam a comparação de suas ações com as de grandes generais da história clássica, como na vitória realizada de dentro do território bohemio descrito no capítulo XXI do III livro: "então Bolesław, o guerreiro, seguido de uma horda de combatentes, abriu um novo caminho para a Bohemia, um maravilhoso feito pelo qual ele podia ser comparado a Hanibal. Pois, como este na sua marcha contra Roma pelo esquecido caminho do monte de Júpiter" ${ }^{\text {’3 }}$. As virtudes da guerra não eram somente atributos de ação, mas também de sabedoria. $\mathrm{O}$ rei tinha de ser sábio, conseguir tomar as decisões mais certas e frutíferas. Aquele que possui mais qualidades pode e deve ser o único a conseguir guiar e instruir na guerra e nas decisões do cotidiano. Por isso, as virtudes devem aparecer no texto da $G p P$ e solidificar os Piastes como exemplo que deve ser obedecido, protegido e seguido.

Os trechos acima citados provam que o grupo interno dos Polanos possui uma tendência a conhecer os grandes nomes da história até aquele momento, sendo que, por isso, a maior parte dos citados tem uma ligação direta com o ato guerreiro. Elevar seu

\footnotetext{
${ }^{34}$ Inder belliger Bolezlauus, collecta multitudine militari, novam viam aperuit in Bohemiam, quo potest Hannibali facto mirabili comparari. Nam sicut ille Romam impugnaturus per montem Iouis. (GALLUS, Anonymus. Op. cit. p. 254). T.A.
} 
comitente ao mesmo patamar dessas figuras valorizava a situação do rei polano. A própria obra nos mostra a situação contemporânea de Bolesław III. A partir do livro III temos a mudança da "narrativa" para a "narração". ${ }^{35}$ Então, vemos nas páginas desta parte da obra de Galo Anônimo como que a expansão da luta contra paladinos internamente e uma preocupação externa forte, devido aos embates com os imperadores Henrique IV e V. A instrução tem de passar uma ideologia régia e para isso deve usar esses elementos clássicos, pois, pelo que indica a fonte, a situação era muito delicada e o texto deveria ser claro e direto. Como os textos têm uma "função citativa", isto é, um discurso cita o outro para construir o seu próprio, podemos ver que as virtudes são elementos dos textos clássicos, as quais são retomadas para tentar fazer a monarquia polana se estabelecer nessa região que, há pouco menos de um século, era apenas território de tribos esparsas. Os conceitos e fundamentos ideológicos do passado greco-latino são os preceitos dos ocidentais, transferidos para os eslavos na forma da monarquia legítima dos Piastes.

Michel Zink aponta que:

Atualmente em nosso espírito, a literatura opõe-se a outra disciplinas intelectuais, como a filosofia ou a história, para não falar das matemáticas ou das ciências da natureza. Ela supõe, ao mesmo tempo, sem dúvida confusamente, o fictício e o gratuito. Essas oposições não são verdadeiramente pertinentes para a Idade Média ${ }^{36}$.

As Crônicas e Gestas, por serem textos escritos, têm uma importância ao poder, pois, como registros deste tipo, ganham um caráter jurídico e de veracidade. Escrever é um poder importante, tudo que cerca o texto tem força de superioridade. Os textos nesse

${ }^{35}$ GUIMARÃES, M. L. Estudo das Representações de Monarcas nas Crônicas de Fernão Lopes (séculos XIV e XV): O espelho do Rei: "Decifra-me e te devoro". Tese. Curitiba: Universidade Federal do Paraná, 2004.p.7. O exemplo dado nas crônicas de Fernão Lopes mostra que a idéia do texto mudar sua voz narrativa de passado contado para um presente observado pelo autor tem recorrência em fontes regias. $N$ do $A$.

${ }^{36}$ LE GOFF, J.; SCHIMITT, J.-C. Op. cit. p. 80. 
momento são os únicos modelos autorizados, tudo se consolida na escritura. A própria Bíblia em seu corpo fomenta o valor da escrita e do texto. Contudo, não somente os textos bíblicos são fundamentais para que uma obra seja vista como um símbolo de grandeza e de verdade. As letras antigas são a herança dos medievais, que as imitam e perpetuam; são elementos importantes para a legitimidade de qualquer texto produzido. Os textos mais recentes devem imitar os clássicos, primeiro, por serem a norma e base do conhecimento e, segundo, para parecerem ter a mesma origem. A crônica de Galo tenta utilizar a força da escrita e incorporar seu texto aos contemporâneos no que tange à veracidade, à importância e à legitimidade. A latinidade monopoliza a intelectualidade. $\mathrm{O}$ ensino não pode estar desvinculado da leitura dos clássicos, a educação é baseada no latim e as artes liberais, as artes técnicas, a medicina, o direito e a história são frutos de uma mescla da educação clássica latina com as novas abordagens cristãs do mundo. A validação do texto do autor, bem como o reconhecimento do reino, passam pela analogia com outros mitos políticos clássicos. Afinal, como mostra Ernst Curtius, todos os escritos latinos são didaticamente dotados de autoridade $^{37}$. Fazer o texto em latim é mais que a forma aceita, é introduzir sua obra no rol de documentos válidos e equipará-lo aos escritos militares de outras épocas ou de outros pontos da Cristandade do século XII, nas palavras de Galo: "Ficaria a fama marcial dos Romanos ou dos Gauleses tão celebrada ao redor do mundo, se não fosse preservada nos testemunhos dos escritores para a posteridade, para lembrar e imitar?",38.

\section{5 - Considerações finais}

\footnotetext{
${ }^{37}$ CURTIUS, E. Literatura européia. São Paulo: EDUSP, 2001. p. 85.

38 Nunquid enim fama vel militia Romanorum vel Gallorum sic celeberrima per mundum haeretur, nisi scriptorum testimoniis memorie posterorum et imitationi servaretur. (GALLUS, Anonymus. Op. cit. p. 212). T.A.
} 
A crônica latina de Galo Anônimo é posta pelo autor, sem vanglórias, em patamares que a deixam em posição de igualdade para com os demais textos latinos que falem sobre os feitos militares, lembrando mais uma vez como Polanos e Romanos podem ter algo em comum. Se Bolesław tem as glórias que fizeram os Romanos ser o que foram, os Polanos também conseguem ter seus feitos militares imortalizados e ter o seu próprio texto latino, totalmente dotado de legitimidade. A violência que existe na Idade Média polana não é a violência que temos, mas sim a que existe como parte do teor da vida dessas pessoas. Uma violência que cria e mantém a sociedade funcionando de acordo com o que estes grupos tinham como inteligível. A figura do rei guerreiro é uma base para que se crie uma instituição cultural própria para os Polanos, que ainda no século XII estão tentando criar sua própria hierarquização e sua função dentro da Cristandade latina.

Encerramos colocando que as fontes eslavas ainda estão sendo pesquisadas e editadas por universidades norte-americanas e européias, constituindo um corpus textual que auxilia no conhecimento de como a cristandade tem facetas distintas em cada centro a que sua maneira de pensar a vida chega. Produzidas por "homens de saber" de diversos períodos, elas mostram como Galo Anônimo é um exemplo de singularidades que contribuem para o entendimento de cada espécie de momento histórico. Convidamos os pesquisadores por meio deste trabalho a se aventurarem nas pesquisas sobre os eslavos medievais para enriquecer o conhecimento histórico sobre esses grupos que ficaram obscurecidos por causa das políticas contemporâneas.a imagem do rei guerreiro é apenas uma das possibilidades de estudo que Galo Anônimo legou ao mundo eslavo cristão.

\section{FONTE PRIMÁRIA}


GALLUS ANONYMUS. Gesta principium Polonorum. The Deeds of The Princes of the Poles. trad. para o inglês de Paul W. Knoll \& Frank Schaer. Budapeste/New York: Central European University Press, 2003.

\section{BIBLIOGRAFIA}

CURTIUS, E. Literatura Européia e Idade Média Latina. São Paulo: EDUSP, 2001.

BOUlHOSA, P. P. Sagas Islandesas como fonte de história Escandinava medieval. Signum, Porto Alegre, n. 7, p.25, 2005.

DALEWSKI, Z. Rytuat i polityka. Październik: Instytut Historii PAN, 2005.

DUBY, G. As três ordens ou o imaginário do feudalismo. Lisboa: Editorial Estampa, 1994.

DUMÉZIL, G. Heur et malheur du guerrier: aspects mythiques de la function guerrière chez les indo-européens. 2. ed. rem. Paris: Flammarion, 1985.

GUIMARÃES, M. L. Estudo das Representações de Monarcas nas Crônicas de Fernão Lopes (séculos XIV e XV): O espelho do Rei: "Decifra-me e te devoro". Tese. Curitiba: Universidade Federal do Paraná, 2004.

LE GOFF, J.; SCHIMITT, J.-C. Dicionário temático do ocidente medieval. Bauru: EDUSC, 2002.

LOYN, H. G. Dicionário da Idade Média. Rio de janeiro: Jorge Zahar, 1997.

MUCENIECKS SZCZWALINSKI, A. Virtude e conselho na pena de Saxo Grammaticus (XII-XIII). Dissertação. Curitiba: Universidade Federal do Paraná, 2008.

PEREIRA, M. H. da R. Estudos de história da cultura clássica. Lisboa: Calouste Gulbenkian, 1993.

SANCHEZ GALÁN, P. J. El género historiográfico de la Chronica. Cácers: Universidade de Extremadura, 1994. 
SILVA, M. C. da. Autoridade pública e violência no período Merovíngio: Gregório de Tours e as Bellas Civilia. In: Instituições, Poderes e Jurisdições. Curitiba: Juruá, 2007.

VERGER, J. Homens e saber na Idade Média. Bauru: Edusc, 1999. 